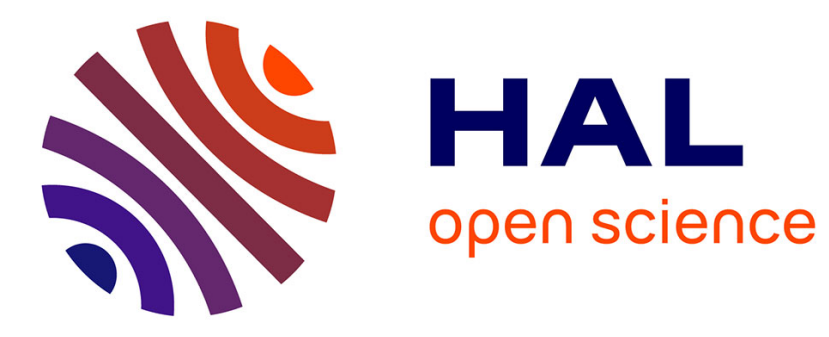

\title{
Lipase diffusion in oil-filled, alginate micro- and macrobeads
}

\author{
Pauline van Leusden, Gertjan J. M. den Hartog, Aalt Bast, Michiel Postema, \\ Erik van Der Linden, Leonard M.C. Sagis
}

\section{- To cite this version:}

Pauline van Leusden, Gertjan J. M. den Hartog, Aalt Bast, Michiel Postema, Erik van Der Linden, et al.. Lipase diffusion in oil-filled, alginate micro- and macrobeads. Food Hydrocolloids, 2018, 85, pp.242-247. 10.1016/j.foodhyd.2018.07.028 . hal-03192786

\section{HAL Id: hal-03192786 \\ https://hal.science/hal-03192786}

Submitted on 15 Apr 2021

HAL is a multi-disciplinary open access archive for the deposit and dissemination of scientific research documents, whether they are published or not. The documents may come from teaching and research institutions in France or abroad, or from public or private research centers.
L'archive ouverte pluridisciplinaire HAL, est destinée au dépôt et à la diffusion de documents scientifiques de niveau recherche, publiés ou non, émanant des établissements d'enseignement et de recherche français ou étrangers, des laboratoires publics ou privés.

\section{(1) (1) $\$$}

Distributed under a Creative Commons Attribution - NonCommercial - NoDerivatives| 4.0 


\section{Lipase diffusion in oil-filled, alginate micro- and}

2 macrobeads

3

4 Authors: P. van Leusden ${ }^{1}$, G.J.M. den Hartog ${ }^{2}$, A. Bast ${ }^{2}$, M. Postema ${ }^{3}$, E. van der Linden ${ }^{1}$,

$5 \quad$ L.M.C. Sagis ${ }^{1 *}$

61 Physics and Physical Chemistry of Foods Group, Department of Agrotechnology and Food

7 Sciences, Wageningen University, Bornse Weilanden 9, 6708 WG Wageningen, The

8 Netherlands

92 Department of Pharmacology and Toxicology, Maastricht University, PO Box 616, 6200

10 MD Maastricht, The Netherlands

Keywords: Oil digestion, microbeads, encapsulation, diffusion, Maxwell-Cattaneo equation

3 School of Electrical and Information Engineering, Chamber of Mines Building, University of the Witwatersrand, 1 Jan Smuts Avenue, Braamfontein, Johannesburg 2050, South Africa.

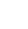

\footnotetext{
* Corresponding author
}

Email address: leonard.sagis@wur.nl 


\section{Abstract}

Triglycerides, which are broken down in the lower part of the intestinal tract, give a stronger ileal brake feedback, resulting in a feeling of satiety and causing people to eat less. The digestion of triglycerides into fatty acids by lipase in the intestine can be delayed by encapsulating oil droplets. In this study the release of fatty acids and oil droplet breakdown in a simulated intestinal system was investigated, for oil droplets encapsulated in alginate micro$(10.7 \mu \mathrm{m})$ and macrobeads $(1.77 \mathrm{~mm})$. It was found that fatty acid release rate was greatly decreased by encapsulating the oil droplets into an alginate matrix compared to loose droplets. Microscopic imaging of the breakdown of the oil droplets showed a sharp front moving from the bead interface to the centre of the bead, and the change in position of the front scaled linear with time. The motion of the front is well described by combining the mass balance for lipase with a Maxwell-Cattaneo type equation, for the mass flux vector. The front in microbeads seemed to move slightly slower $(0.15( \pm 0.04) \mu \mathrm{m}$ per minute) than for the macrobeads $(0.20$ ( \pm 0.02$) \mu \mathrm{m}$ per minute). The release of free fatty acids in microbeads was faster than in macrobeads, despite the slower front movement, because of the larger amount of surface area available. 


\section{Introduction}

Lipids which are digested in the ileum of the intestinal tract induce a negative feedback mechanism, which increases feelings of satiety, causing people to eat less (Alleleyn, van Avesaat, Troost, \& Masclee, 2016; Maljaars, et al., 2011; Spiller, et al., 1984; Welch, Saunders, \& Read, 1985). This effect is called the ileal brake, and is stronger the further along in the intestinal tract the lipids are digested (Welch, et al., 1985). Forcing lipids to be digested further down the intestinal tract might have an application in the treatment or prevention of obesity. Lipase is an enzyme, which breaks down triglycerides into glycerol and free fatty acids (FFA), and is active at the oil-water interface. Therefore most systems intending to delay lipid digestion are based on decreasing the accessibility of lipase to the triglyceride interface. One method to slow the diffusion of lipase to the oil-water interface is by encapsulating oil droplets into a hydrogel bead, where the porous gel acts as a barrier between the lipase and the oil droplets (Corstens, et al., 2017; Li, Hu, Du, Xiao, \& McClements, 2011). Because the lipase first has to diffuse through the matrix before it reaches the oil droplet interface, fatty acid release can be slowed down until the ileum is reached.

Alginate is a polysaccharide that has often been used for medical purposes, including encapsulation of cells and drugs (Covarrubias, de-Bashan, Moreno, \& Bashan, 2012; Lee \& Heo, 2000; Lim \& Sun, 1980; J. Liu, et al., 2010; Pasparakis \& Bouropoulos, 2006; Sultana, et al., 2000). It is a non-toxic and biodegradable polymer which gels in the presence of divalent cations. The method of gelation is very gentle, and thus appropriate for compounds sensitive to heat or strong chemicals. Paques et al. developed a water-in-oil emulsification method that is capable of creating beads of approximately $10 \mu \mathrm{m}$ (Paques, van der Linden, Sagis, \& van Rijn, 2012; van Leusden, et al., 2017). Because particles smaller than $25 \mu \mathrm{m}$ do not negatively affect sensorial aspects of food, these microbeads can be added without affecting sensorial perception (Tyle, 1993).

The factors that influence the rate of diffusion of components in gels include: gel type (X. C. Liu, et al., 2002; Martinsen, Storrø, \& Skjårk-Bræk, 1992) and density (Corstens, et al., 2017; Martinsen, et al., 1992)), the diffusing component's size (Stewart \& Swaisgood, 1993), shape (Pluen, Netti, Jain, \& Berk, 1999), and charge (Huguet \& Dellacherie, 1996; Stewart, et al., 1993), and environmental conditions such as pH (Huguet, et al., 1996) and ionic strength (Huguet, et al., 1996; Stewart, et al., 1993; van Leusden, et al., 2017). In diffusion in hydrogel beads, also the size of the beads is important (Corstens, et al., 2017; Li, et al., 2011). 
When oil is encapsulated in alginate beads for the delayed release of fatty acids, one cannot change the component (lipase) or environment, because those are naturally present in the human biological system. We can however, control the gel properties. Li et al. showed that the digestion of oil droplets encapsulated in alginate beads decreased with increasing bead size (0.8 to $3.4 \mathrm{~mm}$ ), and increased degree of cross-linking with calcium ( $\mathrm{Li}$, et al., 2011). Corstens et al. also showed that digestion of oil droplets encapsulated in alginate beads decreased with increasing bead size ( 0.55 to $1.15 \mathrm{~mm})$, and with increasing alginate concentration, which influences the mesh size of the alginate gel (Corstens, et al., 2017).

Encapsulating oil droplets in an indigestible hydrogel matrix delays the release of fatty acids in the intestinal tract. The rate of the digestion is entirely dependent on the rate with which lipase is able to diffuse into the bead and reach the oil droplets. In this study we investigated the diffusion of lipase in gelled alginate beads. We investigated the influence of size in a wider range than previously reported: macrobeads of $1.77 \mathrm{~mm}$ vs. microbeads of $10.7 \mu \mathrm{m}$. We determined the rate of free fatty acid release, for both macro and microbeads, and used microscopic imaging to track the breakdown of oil droplets as a function of time. We then model this process by combining the mass balance for diffusion of lipase in the bead with a Maxwell-Cattaneo type equation for the mass flux vector. 


\subsection{Materials}

$\mathrm{CaCl}_{2} .2 \mathrm{H}_{2} \mathrm{O}$, ethanol absolute, $\mathrm{NaOH}, \mathrm{NaCl}$ (Merck millipore, Darmstadt, Germany), Tween 60, Lipase from porcine pancreas (Sigma, Steinheim, Germany), Polyglycerol polyricinoleate (PGPR) 90 Kosher (Danisco, Kopenhagen, Denmark), Medium Chain Triglycerides (MCT) (Miglyol 812 N, Sasol, Germany), and Sodium alginate extracted from brown algae (Algin, Texturas, Barcelona, Spain), were all used as received. Solutions were made in demineralized water.

\subsection{Production of Calcium crystals}

Calcium crystals were made according to the method of Paques et al. (Paques, van der Linden, van Rijn, \& Sagis, 2012). In short: A dispersion was made of 6\% PGPR in MCT oil and allowed to mix for 2 hours. A volume of $5 \%$ of a 0.1 molal $\mathrm{CaCl}_{2} .2 \mathrm{H}_{2} \mathrm{O}$ solution in ethanol was added to this MCT solution and emulsified (Sonicator S-250A sonicator, Branson Ultrasonics, USA) for 2 minutes. The resulting mixture was heated and stirred overnight at 60 ${ }^{\circ} \mathrm{C}$ without cover to allow the ethanol to evaporate, producing a dispersion of calcium crystals in oil.

\subsection{Production of the microbeads}

Oil filled alginate microbeads were made based on the method described by Van Leusden et al. (van Leusden, et al., 2017).The inner oil droplets were made by mixing 5.0\% (w/w) MCT with demi-water containing 0.3\% (w/w) Tween 60 with an Ultra-Turrax (Ultra-Turrax T 25, IKA Werke, Germany) at 8000 rpm for 2 minutes. The emulsion was further homogenized (Delta instruments, Drachten, The Netherlands) at 180 bar for 3 passes. To the emulsion 2.0\% (w/w) alginate was added and allowed to dissolve for 2 hours. While mixing with the UltraTurrax at $8800 \mathrm{rpm}, 10 \%(\mathrm{v} / \mathrm{v})$ of the previous emulsion was slowly added to MCT oil containing 4\% (w/w) PGPR. After full addition the double emulsion was mixed for a further 3 minutes. After mixing, $5 \mathrm{~mL}$ of calcium crystal dispersion was added per $\mathrm{mL}$ of primary emulsion. This mixture was gently stirred for at least 18 hours to allow gelation of the beads.

The beads were removed from the oil phase by successive centrifugation and redispersion steps. The beads were centrifuged for 2 hours at $3500 \mathrm{~g}$. The pellet was redispersed in $25 \mathrm{mM}$ $\mathrm{CaCl}_{2}$ solution, homogenised at 100 bar for 3 passes and then once again centrifuged at 1000 
$\mathrm{g}$ for 1 hour. The sediment was redispersed in demi-water, after which the centrifugation was repeated. The highly concentrated beads were stored in demi-water and diluted before use.

\subsection{Production of the macrobeads}

Oil filled alginate macrobeads were made based on the method described by (van Leusden, et al., 2017). The inner oil droplets with alginate were made as described in the section of the production of microbeads. The emulsion was put in a syringe and expressed through a needle of $0.3 \mathrm{~mm}$ (BD Microlance $0.3 \times 13 \mathrm{~mm}$ ) into a $25 \mathrm{mM} \mathrm{CaCl}_{2}$ water bath, where the droplets were formed approximately $5 \mathrm{~cm}$ above water level. The beads were stirred for 1 hour and then stored in the $\mathrm{CaCl}_{2}$ solution, at $4{ }^{\circ} \mathrm{C}$, for a further 24 hours. The beads were taken from the $\mathrm{CaCl}_{2}$ solution, the excess $\mathrm{CaCl}_{2}$ solution was absorbed with filter paper, and the beads were stored at high concentrations in demi-water.

\subsection{Size determination}

The size of the beads was measured by light microsocopy (Axioskop 50) equipped with a camera (AxioCam HRc) (both from Zeiss, Germany). Images were analysed with ImageJ.

\subsection{Lipase accessibility}

The lipase accessibility to the oil droplets was investigated in: 1) a 2.0\% (v/v) dispersion of microbeads, 2) a $2.0 \%$ (v/v) dispersion of macrobeads, 3) an equivalent amount of nonencapsulated emulsion, as made for the production of the alginate beads, but before addition of the alginate. The volume fraction was estimated by drying samples of the beads overnight in an oven at $105^{\circ} \mathrm{C}$. The dry weight of the beads was used to calculate the volume fraction of the beads, assuming no loss of oil occurred. The accessibility was measured in a diluted, simulated intestinal system based on the system described by (Minekus, et al., 2014). This consisted of $150 \mathrm{mM}$ of $\mathrm{NaCl}$ and $1 \mathrm{mg} / \mathrm{mL}$ pancreatic lipase at $\mathrm{pH} 7.0$ and $37^{\circ} \mathrm{C}$. The conversion of MCT to the acidic fatty acids was followed by the amount of $\mathrm{NaOH}$ that needed to be added to keep the $\mathrm{pH}$ at 7.0. This was done with the pH-STAT (Metrohm, Herisau, Switzerland). The reaction was followed for 2.5 hours and duplicate experiments were performed. The free fatty acid release was calculated with the following equation:

$$
\text { FFA } \%=\frac{V_{N a O H} M_{N a O H} M_{w, l i p i d}}{3 \omega_{\text {lipid }}}
$$

where $V_{\mathrm{NaOH}}$ is the volume of $\mathrm{NaOH}$ titrated into the solution to keep it at $\mathrm{pH} 7.0, M_{\mathrm{NaOH}}$ the molarity of the $\mathrm{NaOH}$ solution, $M_{\mathrm{w}, \text { lipid }}$ the average molecular weight of the MCT oil, which 
was calculated to be $508 \mathrm{~g} / \mathrm{mol}$ (based on the composition specified by the manufacturer), and $\omega_{\text {lipid }}$ the fraction of lipid present in the beginning of the experiment. The factor 3 is present because every triglyceride contains 3 fatty acids which can be released.

The oil droplet breakdown was also followed with light microscopy. The same method as for the pH-STAT was used, and at regular time intervals a small sample of the solution was taken. The sample was immediately heated to $80^{\circ} \mathrm{C}$ for 10 minutes to inactivate the lipase. For every sample at least 25 microbeads were investigated in the range of 9.0 to $12 \mu \mathrm{m}$. The macrobeads were cut in half and viewed in a microscope slide with a dip, to prevent the pressure of the cover slide to influence the measurements. For every sample at least four macrobeads were investigated, and the location of the breakdown front was determined at different points along the circumference of the bead. 


\section{Results and Discussion}

157

158

\subsection{FFA digestion and release}

The amount of free fatty acids (FFA) released from oil droplets encapsulated in microbeads and macrobeads, and non-encapsulated droplets, over time is presented in Figure 1. Approximately $70 \%$ of the lipids of the non-encapsulated droplets were digested and released from the oil droplets within 6 minutes. After this point, the breakdown proceeds more slowly. This change in rate could be the result of the fact that pancreatic lipase can cut the fatty acids from the 1 and 3 position from the glycerol backbone very quickly, while the fatty acid from the 2 position of the monoglyceride occurs only after isomerisation of the monoglyceride (Borgström, 1964; Korn, 1961; Mattson \& Beck, 1956). In addition, as a result of the breakdown, the available surface area is reduced, and the fraction of lipase which participates in the process is reduced.

As can be seen in Figure 1, the rate of lipolysis of encapsulated oil droplets is far slower than for non-encapsulated droplets. Lipase first needs to diffuse to the oil-water interface of the oil droplets, and adsorb at this interface. For non-encapsulated droplets in a stirred vessel, this adsorption process is fast. For encapsulated oil droplets, lipase first has to diffuse through the gel matrix of the beads before it can adsorb at the oil-water interface (Corstens, et al., 2017; Li, et al., 2011). After 2.5 hours, $9.0 \%$ of the lipids in the macrobeads has been broken down. The amount of FFA released is almost linear in time, which means the release rate is nearly constant up to $150 \mathrm{~min}$. For the microbeads, after $150 \mathrm{~min}$, approximately $80 \%$ of the lipids has been broken down. Here, the rate of lipid breakdown decreases over time. The difference between micro- and macrobeads can be explained by the difference in specific surface area of the beads. It is known that lipase diffuses more slowly through a gelled matrix than in a solution.

The progression of oil droplet breakdown in time in macro- and microbeads was followed by microscopy (Figure 2, and 3).

As can be seen from the images, for both the micro- and macrobeads there appears to be a front moving inwards over time, separating a volume where oil-droplets have been broken down, from a volume where they appear to be unaffected. The fact that an inward moving front is visible indicates that the breakdown process is diffusion limited, and that the diffusion process itself is non-Fickian. From a previous study it is known that BSA, which has a radius 
of $3.9 \mathrm{~nm}$ (Pluen, et al., 1999), diffuses throughout similarly made micro- and macrobeads within several minutes (van Leusden, et al., 2017). Lipase is smaller than BSA (2.8 nm) (Pignol, et al., 2000) and the salt concentration in the current study is higher (100 vs. $150 \mathrm{mM}$ $\mathrm{NaCl}$ ), so we would expect lipase diffusion through the gel matrix of the bead to be faster. However, when the lipase diffuses into the beads and encounters an oil droplet, it will adsorb on the oil-water interface, and will essentially be trapped there until the oil droplet is digested. When the volume fraction of encapsulated droplets is high enough, this trapping will result in an effective diffusion process with a non-Fickian appearance. Additionally, it is possible that the presence of the lipase in the pores of the alginate gel may thereby also block other lipase molecules of diffusing through.

\subsection{Displacement of the oil front}

The displacements of the fronts for both macro and microbeads were determined from image analysis of Figure 2, and Figure 3. The results are shown in Figure 4.

For the macrobeads, the displacement of the front is linear in time, which corresponds to the release of FFA, which was also linear in time. After 2.5 hours, the front has moved approximately $30 \mu \mathrm{m}$ inwards. The amount of oil in this $30 \mu \mathrm{m}$ shell corresponds to approximately $9.7 \%$ of the total oil content. As shown in Figure 1, the release rate after 2.5 hours is approximately $9.0 \%$. This confirms that the breakdown of oil indeed proceeds from the outward in.

The displacement of the front in the microbeads is also linear in time. The oil of the beads with a diameter in the range of 9 to $12 \mu \mathrm{m}$ is mostly broken down within 80 minutes, which is in reasonable agreement with the FFA release data. The difference between these two measurements is the result of the polydispersity of the beads. For our image analysis we investigated mainly beads between 9 and $12 \mu \mathrm{m}$. There is however also a fraction of beads smaller than $9 \mu \mathrm{m}$ and another fraction of beads larger than $12 \mu \mathrm{m}$. Larger beads release their oil slowly, because of their lower specific surface area. After 2.5 hours there were still several bigger microbeads, of approximately $50 \mu \mathrm{m}$, that still had not released all their oil, and this is why in the FFA release graph only $80 \%$ of the oil of the microbeads is released. The rate of front displacement in the macrobeads is approximately $0.20( \pm 0.02) \mu \mathrm{m}$ per minute, while for the microbeads this is approximately $0.15( \pm 0.04) \mu \mathrm{m}$ per minute (calculated from the average bead size of $10.7 \mu \mathrm{m})$. 
245

\subsection{Modelling of lipolysis kinetics}

Both Li et al. and Corstens et al. have developed models for the diffusion of lipase through alginate microbeads (Corstens, et al., 2017; Li, et al., 2011). The model of $\mathrm{Li}$ et al. did not fit the experimental results very well, for which they give several possible explanations. The pore size they assumed is most likely much smaller than the actual pore size, as found by Corstens et al., which dramatically reduces the diffusion coefficient. They also suggest that lipase may interact with the gel network, where we assume that lipase in fact interacts with the oil droplets, thereby also resulting in hindered diffusion.

Corstens et al. have used Fick's law to calculate the concentration of enzyme at a certain position in their beads. For the large beads we will assume the effects of curvature are negligible, and we will describe the diffusion process as a one-dimensional diffusion problem in a Cartesian coordinate system $(x, y, z)$. According to Fick's law the mass flux of lipase in the $x$-direction is given by

$J_{x}=-D \frac{\partial C}{\partial x}$

Where $J_{x}$ is the flux in $\mathrm{mol} / \mathrm{m}^{2} \mathrm{~s}, \mathrm{D}$ is the diffusion coefficient in $\mathrm{m}^{2} / \mathrm{s}$, and c is the concentration in $\mathrm{mol} / \mathrm{m}^{3}$.

A drawback of this model is that when combined with the mass balance for lipase, we obtain a parabolic partial differential equation, which predicts an unbounded speed of propagation of concentration perturbations. In our case however we have seen a clear front moving through the bead at a finite speed. To alleviate this problem we replace Eq. (1) by a Maxwell-Cattaneo type equation for the mass flux. The Maxwell-Cattaneo equation is an adaption of Fourier's law for heat conduction, where a characteristic time is introduced to avoid an unbounded speed of propagation of thermal perturbations (Jou, Casas-Vázquez, \& Lebon, 2010). For mass diffusion this equation is formulated as:

$\tau \frac{\partial J_{x}}{\partial t}+J_{x}=-D \frac{\partial C}{\partial x}$

Here $t$ is time, and $\tau$ is the retardation time, in s. Combining this expression for the mass flux with the differential mass balance for lipase, we obtain (see Appendix)

$\frac{\partial^{2} C}{\partial t^{2}}+\frac{1}{\tau} \frac{\partial C}{\partial t}-\frac{D}{\tau} \frac{\partial^{2} C}{\partial x^{2}}=0$ 
$248 v=\sqrt{\frac{D}{\tau}}$ time, i.e.

This is a telegraph equation, a hyperbolic partial differential equation which predicts a finite speed of propagation for concentration perturbations, $v$, given by:

When $v$ is constant, (3) predicts a front displacement $L$ for the large beads, which is linear in

$L \sim\left(\sqrt{\frac{D}{\tau}}\right) t$

For the small beads, following along the same lines, we also find a relative front displacement which is linear in time. Both scalings are confirmed by our experimental results (see Fig. 4).

To establish the limits of validity of the model we present here, and compare it to the other models (Corstens, et al., 2017; Li, et al., 2011), we need to consider the processes of diffusion, adsorption and digestion in more detail. The beads are a complex multiphase system, in which the lipase diffuses through the matrix of the bead (and interacts with this matrix), until it encounters an oil droplet. It then adsorbs at the interface, after which it starts to digest the oil droplet. After digestion, the desorbed lipase can continue its path through the matrix, until it reaches another droplet. By assuming Eq (2) we describe this complex diffusion-adsorption-reaction system on a coarse-grained level, and approximate the structure of the beads as a single effective medium. On this coarse-grained level the diffusion of the lipase through the bead is quantified by the coefficient $\mathrm{D}$. On its path the lipase is retarded by the matrix and by adsorption to the oil droplets, and this is characterized by the retardation time. Such a coarse-grained model will give good results, as long as the matrix is homogeneous, with small pores, and oil droplets are small and homogeneously dispersed throughout the bead.

In systems with small pores and homogeneously dispersed droplets the retardation time will be longer, which will give a slower propagation speed. In systems with bigger pores and small numbers of large oil droplets the retardation time will be shorter, thereby increasing the propagation speed. For such systems the process will more closely resemble the diffusion according to Fick's second law (note that Eq (2) reduces to that equation in the limit that $\tau$ goes to zero). Corstens et al. have used Fick's law to describe their systems (Corstens, et al., 2017). This gave a good description of their data since their beads contained a small number 
275 of large oil droplets ( $\mathrm{D}_{32}=21 \pm 4 \mu \mathrm{m}$ ), whereas ours contain a large number of relatively

276 small ones (approximately $1 \mu \mathrm{m}$ ). The surface to volume ratio is smaller in larger droplets,

277 and therefore less surface is available for lipase entrapment. In their study the retardation

278 effects are therefore much smaller. The model of Corstens et al. has proven to be adequate for

279 several alginate macrobead systems. In our system however, where a clear, linear front was

280 visible over a prolonged length of time, retardation effects were significant, and the Maxwell-

281 Cattaneo equation provided a better description of the dynamics of the system. 


\section{Conclusions}

Lipid digestion was slowed by encapsulating oil droplets into an alginate matrix, because the alginate creates a barrier that lipase first has to diffuse through before it is able to attach to the interface of the oil droplets. Once lipase is bound at the interface it is trapped until the droplet is digested, which retards lipase diffusion. The breakdown of oil droplets in the alginate beads proceeded from the outside of the bead to the centre, where a clear front was present during digestion. The progression of the front was linear and could be described best by a MaxwellCattaneo type equation for the mass flux, instead of the normally used Fick's law. For microbeads this front seemed to move slightly slower at $0.15( \pm 0.04) \mu \mathrm{m}$ per minute than for macrobeads, $0.20( \pm 0.02) \mu \mathrm{m}$ per minute. Despite the similar front speed, the oil in the microbeads digested much faster than the oil in microbeads because of the larger amount of surface area available. 
297 The research presented in this paper was financially supported by the Graduate School 298 VLAG, of Wageningen University. 


\section{References}

Alleleyn, A., van Avesaat, M., Troost, F., \& Masclee, A. (2016). Gastrointestinal Nutrient Infusion Site and Eating Behavior: Evidence for A Proximal to Distal Gradient within the Small Intestine? Nutrients, 8(3), 117.

Borgström, B. (1964). Influence of bile salt, $\mathrm{pH}$, and time on the action of pancreatic lipase; physiological implications. Journal of lipid research, 5(4), 522-531.

Corstens, M. N., Berton-Carabin, C. C., Elichiry-Ortiz, P. T., Hol, K., Troost, F. J., Masclee, A. A. M., \& Schroën, K. (2017). Emulsion-alginate beads designed to control in vitro intestinal lipolysis: Towards appetite control. Journal of Functional Foods, 34(Supplement C), 319-328.

Covarrubias, S. A., de-Bashan, L. E., Moreno, M., \& Bashan, Y. (2012). Alginate beads provide a beneficial physical barrier against native microorganisms in wastewater treated with immobilized bacteria and microalgae. Applied Microbiology and Biotechnology, 93(6), 2669-2680.

Huguet, M. L., \& Dellacherie, E. (1996). Calcium alginate beads coated with chitosan: Effect of the structure of encapsulated materials on their release. Process Biochemistry, 31(8), 745-751.

Jou, D., Casas-Vázquez, J., \& Lebon, G. (2010). Extended Irreversible Thermodynamics: Evolution Equations. In Extended Irreversible Thermodynamics (pp. 42-58). Dordrecht: Springer Netherlands.

Korn, E. D. (1961). The fatty acid and positional specificities of lipoprotein lipase. Journal of Biological Chemistry, 236(6), 1638-1642.

Lee, K.-Y., \& Heo, T.-R. (2000). Survival of Bifidobacterium longumImmobilized in calcium alginate beads in simulated gastric juices and bile salt solution. Applied and Environmental Microbiology, 66(2), 869-873.

Li, Y., Hu, M., Du, Y., Xiao, H., \& McClements, D. J. (2011). Control of lipase digestibility of emulsified lipids by encapsulation within calcium alginate beads. Food Hydrocolloids, 25(1), 122-130.

Lim, F., \& Sun, A. M. (1980). Microencapsulated islets as bioartificial endocrine pancreas. Science, 210(4472), 908-910.

Liu, J., Zhang, Y., Wang, C., Xu, R., Chen, Z., \& Gu, N. (2010). Magnetically sensitive alginate-templated polyelectrolyte multilayer microcapsules for controlled release of doxorubicin. The Journal of Physical Chemistry C, 114(17), 7673-7679.

Liu, X. C., Yu, W. Y., Zhang, Y., Xue, W. M., Yu, W. T., Xiong, Y., Ma, X. Y., Chen, Y., \& Yuan, Q. (2002). Characterization of structure and diffusion behaviour of Ca-alginate beads prepared with external or internal calcium sources. Journal of Microencapsulation, 19(6), 775-782.

Maljaars, P., Peters, H. P., Kodde, A., Geraedts, M., Troost, F. J., Haddeman, E., \& Masclee, A. A. (2011). Length and site of the small intestine exposed to fat influences hunger and food intake. British journal of nutrition, 106(10), 1609-1615.

Martinsen, A., Storrø, I., \& Skjårk-Bræk, G. (1992). Alginate as immobilization material: III. Diffusional properties. Biotechnology and Bioengineering, 39(2), 186-194.

Mattson, F., \& Beck, L. (1956). The specificity of pancreatic lipase for the primary hydroxyl groups of glycerides. Journal of Biological Chemistry, 219(2), 735-740.

Minekus, M., Alminger, M., Alvito, P., Ballance, S., Bohn, T., Bourlieu, C., Carrière, F., Boutrou, R., Corredig, M., \& Dupont, D. (2014). A standardised static in vitro 
digestion method suitable for food-an international consensus. Food \& function, 5(6), 1113-1124.

Paques, J. P., van der Linden, E., Sagis, L. M. C., \& van Rijn, C. J. M. (2012). Food-Grade Submicrometer Particles from Salts Prepared Using Ethanol-in-Oil Mixtures. Journal of Agricultural and Food Chemistry, 60(34), 8501-8509.

Paques, J. P., van der Linden, E., van Rijn, C. J. M., \& Sagis, L. M. C. (2012). Alginate submicron beads prepared through w/o emulsification and gelation with $\mathrm{CaCl} 2$ nanoparticles. Food Hydrocolloids, 31(2), 428-434.

Pasparakis, G., \& Bouropoulos, N. (2006). Swelling studies and in vitro release of verapamil from calcium alginate and calcium alginate-chitosan beads. International Journal of Pharmaceutics, 323(1-2), 34-42.

Pignol, D., Ayvazian, L., Kerfelec, B., Timmins, P., Crenon, I., Hermoso, J., FontecillaCamps, J. C., \& Chapus, C. (2000). Critical role of micelles in pancreatic lipase activation revealed by small angle neutron scattering. Journal of Biological Chemistry, 275(6), 4220-4224.

Pluen, A., Netti, P. A., Jain, R. K., \& Berk, D. A. (1999). Diffusion of Macromolecules in Agarose Gels: Comparison of Linear and Globular Configurations. Biophysical journal, 77(1), 542-552.

Spiller, R., Trotman, I., Higgins, B., Ghatei, M., Grimble, G., Lee, Y., Bloom, S., Misiewicz, J., \& Silk, D. (1984). The ileal brake--inhibition of jejunal motility after ileal fat perfusion in man. Gut, 25(4), 365-374.

Stewart, W. W., \& Swaisgood, H. E. (1993). Characterization of calcium alginate pore diameter by size-exclusion chromatography using protein standards. Enzyme and microbial technology, 15(11), 922-927.

Sultana, K., Godward, G., Reynolds, N., Arumugaswamy, R., Peiris, P., \& Kailasapathy, K. (2000). Encapsulation of probiotic bacteria with alginate-starch and evaluation of survival in simulated gastrointestinal conditions and in yoghurt. International Journal of Food Microbiology, 62(1-2), 47-55.

Tyle, P. (1993). Tactile Pattern RecognitionEffect of size, shape and hardness of particles in suspension on oral texture and palatability. Acta Psychologica, 84(1), 111-118.

van Leusden, P., den Hartog, G. J. M., Bast, A., Postema, M., van der Linden, E., \& Sagis, L. M. C. (2017). Permeation of probe molecules into alginate microbeads: Effect of salt and processing. Food Hydrocolloids, 73(Supplement C), 255-261.

Welch, I., Saunders, K., \& Read, N. W. (1985). Effect of ileal and intravenous infusions of fat emulsions on feeding and satiety in human volunteers. Gastroenterology, 89(6), 12931297. 
387 We start by rewriting (2) as:

$388 \quad \frac{\partial J_{x}}{\partial t}=-\frac{D}{\tau} \frac{\partial C}{\partial x}-\frac{1}{\tau} J_{x}$

389 In a Cartesian coordinate system the mass balance for the lipase is given by:

$390 \quad \frac{\partial C}{\partial t}=-\frac{\partial J_{x}}{\partial x}$

391 Taking the derivative with respect to time of this equation, we obtain:

$392 \quad \frac{\partial^{2} C}{\partial t^{2}}=-\frac{\partial}{\partial x}\left(\frac{\partial J_{x}}{\partial t}\right)$

393 Here we have used the fact that $x$ and $t$ are independent variables, and exchanged the order of

394 derivation in the term on the right hand side. When combining equations A.1 and A.3 we find:

$395 \quad \frac{\partial^{2} C}{\partial t^{2}}=\frac{\partial}{\partial x}\left(\frac{D}{\tau} \frac{\partial C}{\partial x}+\frac{1}{\tau} J_{x}\right)$

396 Eliminating the second term on the right hand side, using A.2, we obtain:

$397 \frac{\partial^{2} C}{\partial t^{2}}+\frac{1}{\tau} \frac{\partial C}{\partial t}-\frac{D}{\tau} \frac{\partial^{2} C}{\partial x^{2}}=0$ 
Figures:

400 Figure 1:

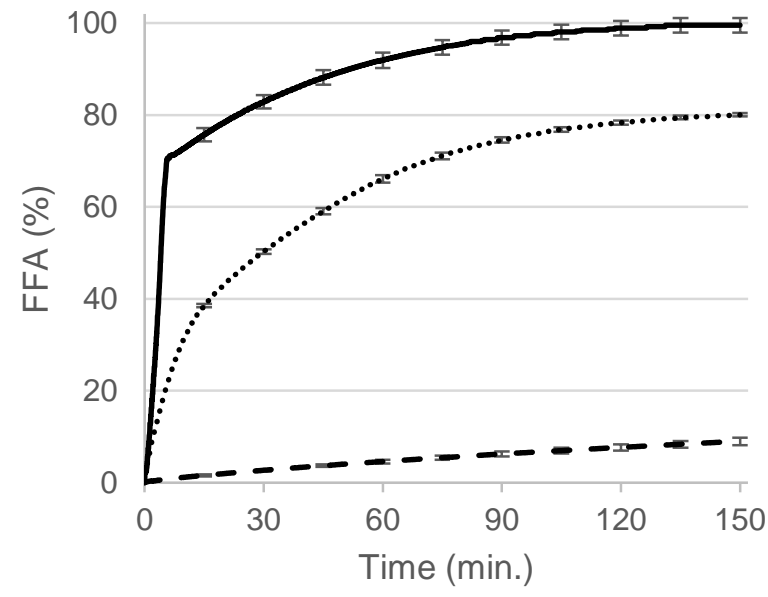

401 
Figure 2:

404
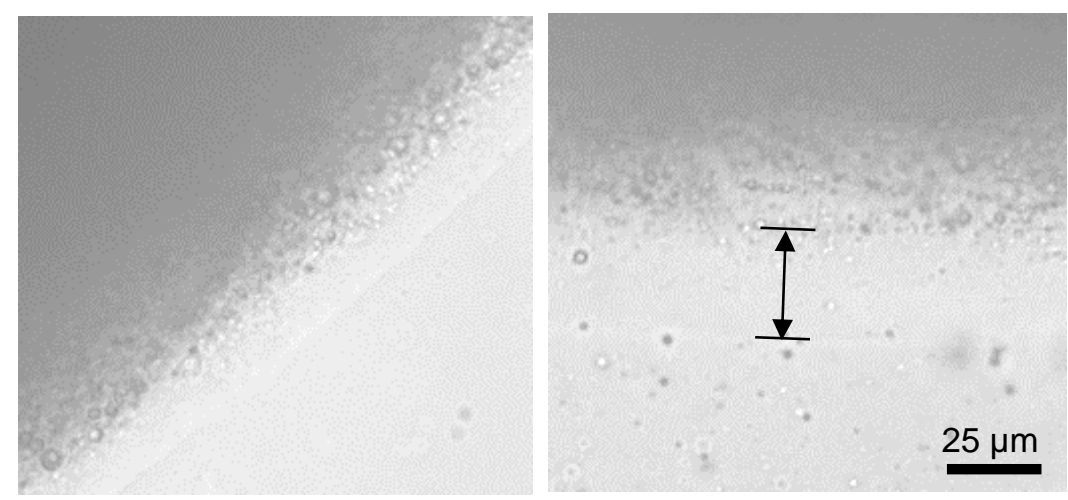

405 
406 Figure 3:

407
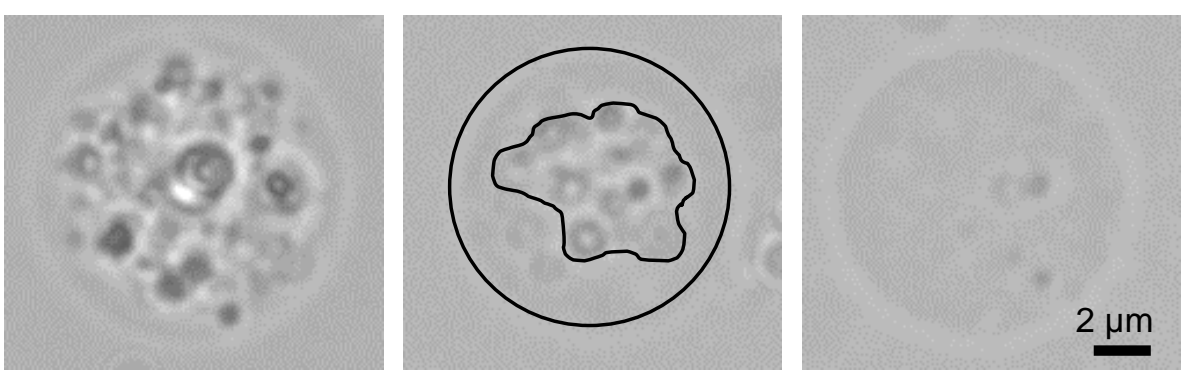

408 
409 Figure 4:

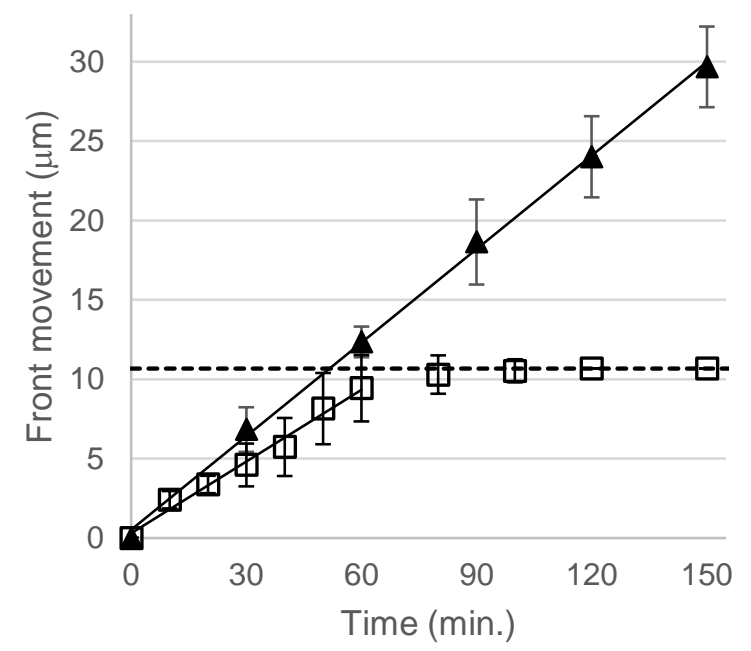

410 